\title{
A LEITURA PARA A EDUCAÇÃO INFANTIL NA BNCC: CONTINUIDADES E RUPTURAS
}

\section{READING IN THE BNCC FOR EARLY CHILDHOOD EDUCATION: RUPTURES AND CONTINUITIES}

\author{
Mellina Silva ${ }^{1}$ \\ Ana Lúcia Guedes-Pinto ${ }^{2}$
}

\begin{abstract}
Resumo: Ao longo das últimas décadas a Educação Infantil tem recebido diversas orientações de documentos oficiais para guiar os fazeres pedagógicos. A Base Nacional Comum Curricular (BNCC), publicada em 2017, entrou para o rol de documentos que prescrevem a educação de todo o país. Desta forma, o objetivo deste artigo é analisar a Prática de Leitura apresentada pela BNCC para a Educação Infantil, buscando encontrar continuidades e rupturas em relação aos documentos oficiais precedentes - Referencial Curricular Nacional para a Educação Infantil (RCNEI) e as Diretrizes Curriculares Nacionais para a Educação Infantil (DCNEI). A pesquisa documental evidenciou que a BNCC apresenta como continuidades: o reconhecimento e o destaque do professor como mediador entre os textos e as crianças, e a leitura de livros literários como principal fonte de leitura; e como ruptura, a ausência de menção ao conceito de letramento como fundamento para o trabalho com a leitura.
\end{abstract}

Palavras-chave: Leitura; Educação Infantil; documentos oficiais.

\begin{abstract}
Over the past decades, early childhood education, the first stage of basic education, received guidance from several documents that guided pedagogical activities. The National Common Curricular Base (BNCC), published in 2017, joined the list of documents that guide education across the our country. Thus, the aim of this work is to analyze what BNCC for early childhood education refers to reading and find continuities and ruptures in the previous official documents - National Curriculum Reference for Early Childhood Education (RCNEI) and the National Curricular Guidelines for Child Education (DCNEI). The documentary research showed that BNCC presents as continuities: teacher as a mediator of texts and children, and reading of literary books as the main source of reading; and ruptures: lack of mention of literacy as a base for Reading work.
\end{abstract}

Keywords: Reading; Child Education; official documents.

\section{Introdução}

Este trabalho tem o objetivo de analisar as orientações da Base Nacional Comum Curricular (BNCC) sobre a prática da leitura na Educação Infantil, e buscar apontar possíveis continuidades e rupturas entre este documento e os materiais oficiais precedentes do Ministério da Educação (MEC) - Referencial Curricular Nacional para a Educação Infantil (RCNEI) e as Diretrizes Curriculares Nacionais para a Educação Infantil (DCNEI) - que procuraram fornecer parâmetros para esse segmento educacional.

Para tal, procedemos da seguinte forma: expor as conceituações sobre leitura descritas na Base (BNCC) para posteriormente confrontá-las aos materiais do MEC que embasaram o trabalho na Educação Infantil nas últimas décadas.

\footnotetext{
${ }^{1}$ Universidade Estadual de Campinas, Campinas, SP, Brasil.

${ }^{2}$ Universidade Estadual de Campinas, Campinas, SP, Brasil.
} 
Este estudo ${ }^{3}$, buscou perceber e/ou sinalizar algumas ações, mudanças e mesmo alguns movimentos em torno da prática leitora no que se refere às recomendações oficiais sobre como se proceder com a leitura nas instituições educacionais. Em relação à tarefa de analisar documentos, Godoy (1995) salienta que o analista/pesquisador depreende de duplo esforço: "entender o sentido da comunicação, como se fosse o receptor normal, e, principalmente, desviar o olhar, buscando outra significação, outra mensagem, passível de se enxergar por meio ou ao lado da primeira" (p. 23). Fazendo uma analogia à perspectiva de Ginzburg (1989), poderíamos denominar esse 'desvio do olhar' como uma postura adotada pelo paradigma indiciário. Para o autor, a pesquisa em possíveis pistas discursivas em documentos, em obras de arte como a pintura e as esculturas, em imagens da sociedade e sua relação com a natureza ou a própria realidade, chamam o pesquisador a olhar o objeto pesquisado buscando um conjunto de indícios que podem não estar muito evidentes, escondidos em um senso comum, por exemplo, às vezes se tornando visível pelo inusitado. Nas palavras do autor, a procura por vestígios está "em indícios imperceptíveis para a maioria" (GINZBURG, 1989 p. 145), encontra-se em "sutilezas certamente nãoformalizáveis" (ibidem, p. 167), está "nos pormenores mais negligenciáveis e menos influenciados" (ibidem, p. 144). Ambos os autores destacam que a postura de investigação de um pesquisador requer cuidado e atenção, com a finalidade de se perceber nuances, pequenas variações naquilo que se deseja problematizar.

A leitura, na perspectiva aqui assumida, é compreendida como uma prática sociocultural e política, ao mesmo tempo que também considerada em seu caráter cognitivo tendo em vista a mobilização intelectual investida na atividade de ler. Em outras palavras, o ato de ler envolve operações mentais que são protagonizadas pelo leitor em sua atividade cognitiva e social. A leitura pressupõe interação entre o leitor, o autor (escritor) e seu contexto (imediato e mediato), tanto no caso da leitura realizada por uma única pessoa quanto no caso de ser realizada de forma compartilhada (BICALHO, 2015?); e também se configura como uma atividade política, uma vez que o ato de ler incide em uma escolha do leitor, a intenção em ler determinado texto (e não outro) e, nesse aspecto, se ressalta a questão ideológica que envolve o ato de ler (FREIRE, 1989).

É importante lembrar que, ao tomar os documentos oficiais como fonte de análise, assume-se o pressuposto de que tais documentos apresentam certas concepções de educação (nem sempre explicitadas), procurando garantir um caráter universal, a fim de que possa de fato converter-se em um documento regulador para o campo em questão. Foucault (1988), ao problematizar as relações de poder, utiliza o termo biopolítica para descrever os procedimentos do Estado sobre a vida dos indivíduos e da gestão da massa social. A escola, por sua vez, integra, sob o viés dessa abordagem, uma das instituições sociais que garante a formação da sociabilidade e, segundo ele, da modelagem de indivíduos.

O estudo de documentos oficiais colabora com a desmistificação de conceitos neles apresentados. Freire (1996) chama atenção sobre a importância de duvidar e questionar os preceitos normalmente traçados para a educação. Por essa perspectiva de analisar com cuidado certas regulamentações institucionais, este artigo busca compreender as prerrogativas do MEC assumidas na BNCC em relação à leitura para o segmento da Educação Infantil.

\footnotetext{
${ }^{3}$ Trata-se de uma parte de uma pesquisa de Mestrado desenvolvida no contexto do Programa de Pós-Graduação em Educação de uma universidade pública brasileira.
} 


\section{A leitura na BNCC para a Educação Infantil}

Ao ler a Base Nacional Comum Curricular, questionamos alguns pontos: como a leitura está expressa no atual documento para a Educação Infantil? A concepção de leitura assumida na BNCC é a mesma de documentos anteriores?

Partindo de tais questionamentos, em um primeiro momento, é preciso lembrar que os documentos oficiais publicados pelo MEC são de cunho legislativo. Em outras palavras, os documentos respondem à legislação vigente do país, procurando atender às reivindicações da sociedade civil organizada e dos órgãos administrativos da federação, que executam as políticas. A Constituição Federal Brasileira, deliberada em 1988, representou um grande avanço à história da educação e aos direitos das crianças. No artigo $205^{\circ}$, que trata da Educação, da Cultura e do Desporto, a Constituição estabelece que a educação é um direito de todos os brasileiros, sendo dever do Estado e da família, à promoção e o incentivo ao "pleno desenvolvimento da pessoa, seu preparo para o exercício da cidadania e sua qualificação para o trabalho" (BRASIL, 1988). A mesma lei ainda assegura a Educação Infantil gratuita em creches e pré-escolas até os cinco anos de idade.

Outra lei que regulamenta a educação é a Lei de Diretrizes e Bases da Educação Nacional (LDBEN, Lei $n^{\circ}$ 9394/96) que incluiu a Educação Infantil como primeira modalidade da educação básica. Esta lei colaborou e fez efervescer a discussão sobre os princípios e fundamentos da educação para a primeira infância.

Diante dos dispositivos legais do Estado, o MEC encarrega-se de compor documentos que orientem a Educação Infantil no âmbito nacional, uma vez que a LDB (1996) enfatiza que “a União incumbir-se-á de (...) estabelecer, em colaboração com os Estados, o Distrito Federal e os Municípios, competências e diretrizes para a Educação Infantil (...) que nortearão os currículos e seus conteúdos mínimos, de modo a assegurar formação básica comum" (BRASIL, 1996). Por sua vez, as creches e pré-escolas deverão "no prazo de três anos, a contar da publicação desta Lei, integrar-se ao respectivo sistema de ensino" (BRASIL, 1996).

Considerando a LDBEN, a BNCC integra o rol de documentos oficiais para a Educação Infantil. Esta estrutura-se em alguns conceitos que os precedentes documentos já apresentavam, como por exemplo, o conceito de criança exposto nas Diretrizes Curriculares Nacionais da Educação Infantil (DCNEI). Em ambos os documentos a criança é tomada como

sujeito histórico e de direitos, que, nas interações, relações e práticas cotidianas que vivencia, constrói sua identidade pessoal e coletiva, brinca, imagina, fantasia, deseja, aprende, observa, experimenta, narra, questiona e constrói sentidos sobre a natureza e a sociedade, produzindo cultura (BRASIL, 2009).

Outra característica que a BNCC se assemelha às DCNEI se refere aos eixos estruturantes de sua organização curricular: interações e brincadeiras. Esses eixos compõem os direitos de aprendizagens e desenvolvimento das crianças na BNCC. Os direitos de aprendizagem e desenvolvimento integram um conjunto de fazeres - pessoais, sociais e naturais - que dão condições às crianças de agirem ativamente sob os ambientes e vivências propostas. Os direitos descritos no documento são arrolados como: conviver, brincar, participar, explorar, expressar e conhecer-se. Destes seis direitos que estão estruturados nos eixos interações e brincadeiras, a Base organiza o currículo para a Educação Infantil em cinco campos de experiências, sendo eles: O eu, o outro e o nós; Corpo, gestos e movimentos; Traços, sons, cores e formas; Escuta, fala, pensamento e imaginação e Espaços, tempos, quantidades, relações e transformações. Estes campos são considerados "um arranjo curricular que acolhe as situações e as experiências 
concretas da vida cotidiana das crianças e seus saberes, entrelaçando-os aos conhecimentos que fazem parte do patrimônio cultural" (BRASIL, 2017, p. 38).

Dentre os campos de experiência, a leitura está sob o campo: 'Escuta, fala, pensamento e imaginação', que apresenta o seguinte conceito:

Desde cedo, a criança manifesta curiosidade com relação à cultura escrita: ao ouvir e acompanhar a leitura de textos, ao observar os muitos textos que circulam no contexto familiar, comunitário e escolar, ela vai construindo sua concepção de língua escrita, reconhecendo diferentes usos sociais da escrita, dos gêneros, suportes e portadores. Na Educação Infantil, a imersão na cultura escrita deve partir do que as crianças conhecem e das curiosidades que deixam transparecer. As experiências com a literatura infantil, propostas pelo educador, mediador entre os textos e as crianças, contribuem para o desenvolvimento do gosto pela leitura, do estímulo à imaginação e da ampliação do conhecimento de mundo. Além disso, o contato com histórias, contos, fábulas, poemas, cordéis etc. propicia a familiaridade com livros, com diferentes gêneros literários, a diferenciação entre ilustrações e escrita, a aprendizagem da direção da escrita e as formas corretas de manipulação de livros. Nesse convívio com textos escritos, as crianças vão construindo hipóteses sobre a escrita que se revelam, inicialmente, em rabiscos e garatujas e, à medida que vão conhecendo letras, em escritas espontâneas, não convencionais, mas já indicativas da compreensão da escrita como sistema de representação da língua. (BRASIL, 2017, p. 40).

O conceito de leitura ao qual o atual documento direciona o trabalho pedagógico apresenta a proposta do convívio com diferentes textos, por meio do qual as crianças construirão sua própria concepção da língua escrita. Neste documento, o educador é identificado como o mediador da leitura e por esta mediação a criança estabelecerá saberes sobre a leitura. O texto do documento se refere à importância dos rabiscos e garatujas, mas não se volta à dinâmica da situação da prática leitora nem às possíveis propostas de encaminhamentos para esses momentos de produção da criança. A produção escrita é descrita posteriormente, no quadro Objetivos de aprendizagens e desenvolvimento, ao qual destaca a escrita espontânea e a escrita estruturada pelo educador, como escriba.

O texto da BNCC expressa, de certa forma, a formação leitora defendida por estudiosos consagrados da área de educação e que já tematizaram a sua importância (embora não voltado a crianças especificamente), como Freire (1989) e Silva (2003). Os autores compreendem a formação leitora na construção de ideias sobre o texto, por meio de rodas de conversa, de debates, nas interações entre todos os participantes, na leitura de mundo que o diálogo entre professor e aluno (educador e criança) pode proporcionar. Essa experiência de apropriação do texto é defendida pelos autores e citada na BNCC:

Progressivamente, as crianças vão ampliando e enriquecendo seu vocabulário e demais recursos de expressão e de compreensão, apropriando-se da língua materna - que se torna, pouco a pouco, seu veículo privilegiado de interação. $\mathrm{Na}$ Educação Infantil, é importante promover experiências nas quais as crianças possam falar e ouvir, potencializando sua participação na cultura oral, pois é na escuta de histórias, na participação em conversas, nas descrições, nas narrativas elaboradas individualmente ou em grupo e nas implicações com as múltiplas linguagens que a criança se constitui ativamente como sujeito singular e pertencente a um grupo social (BRASIL, 2017, p. 40). 
$\mathrm{O}$ documento ainda apresenta os Objetivos de aprendizagem e desenvolvimento que correspondem às aproximações de habilidades que as crianças devam alcançar, ao final da Educação Infantil. Conhecendo quais são as habilidades finais, o educador tem a autonomia em planejar e propor atividades que correspondam às práticas de leituras que envolvam o debate, a discussão e o diálogo e, que por consequência irão corresponder às habilidades esperadas na BNCC. No documento a autonomia do educador é expressa com o termo intencionalidade educativa. Esta intencionalidade se refere às práticas pedagógicas que o educador dispõe para planejar experiências que promovam o desenvolvimento das crianças, cabendo a ele "refletir, selecionar, organizar, planejar, mediar e monitorar o conjunto das práticas e interações, garantindo a pluralidade de situações que promovam o desenvolvimento pleno das crianças" (BRASIL, 2017, p. 37).

Os Objetivos de aprendizagem e desenvolvimento são apresentados em um quadro com a descrição dos objetivos, organizados por três grupos de faixas etárias - Bebês (zero a 1 ano e 6 meses); Crianças bem pequenas ( 1 ano e 7 meses a 3 anos e 11 meses) e Crianças pequenas (4 anos a 5 anos e 11 meses). Nesse quadro descritivo, os objetivos destinados a cada faixa etária são expostos e trazem questões relacionadas à leitura (Figuras 1 e 2), tais como: "demonstrar interesse e atenção ao ouvir a leitura de histórias e outros textos" ou ainda "escolher e folhear livros, procurando orientar-se por temas e ilustrações e tentando identificar palavras conhecidas". Ressalta-se que o enfoque da BNCC sobre a leitura para a Educação Infantil limita-se à leitura de livros e textos em diferentes suportes e gêneros, como se pode constatar no seguinte trecho: "selecionar livros e textos de gêneros conhecidos para a leitura de um adulto e/ou para sua própria leitura" e, "manusear diferentes portadores textuais, demonstrando reconhecer seus usos sociais" (BRASIL, 2017, p. 47-48). 
CAMPO DE EXPERIÊNCIAS “ESCUTA, FALA, PENSAMENTO E IMAGINAÇÃO”

\begin{tabular}{|c|c|c|}
\hline $\begin{array}{l}\text { Bebès (zero a } 1 \text { ano e } \\
6 \text { meses) }\end{array}$ & $\begin{array}{l}\text { Crianças bem pequenas ( } 1 \text { ano } \\
\text { e } 7 \text { meses a } 3 \text { anos e } 11 \text { meses) }\end{array}$ & $\begin{array}{l}\text { Criancas pequenas ( } 4 \text { anos a } \\
5 \text { anos e } 11 \text { meses) }\end{array}$ \\
\hline $\begin{array}{l}\text { (EIO1EFO1) } \\
\text { Reconhecer quando é } \\
\text { chamado por seu nome } \\
\text { e reconhecer os nomes } \\
\text { de pessoas com quem } \\
\text { convive. }\end{array}$ & $\begin{array}{l}\text { (EIO2EFO1) } \\
\text { Dialogar com crianças e } \\
\text { adultos, expressando seus } \\
\text { desejos, necessidades, } \\
\text { sentimentos e opiniōes. }\end{array}$ & $\begin{array}{l}\text { (EIO3EF01) } \\
\text { Expressar ideias, desejos } \\
\text { e sentimentos sobre suas } \\
\text { vivências, por meio da } \\
\text { linguagem oral e escrita } \\
\text { (escrita espontânea), de } \\
\text { fotos, desenhos e outras } \\
\text { formas de expressão. }\end{array}$ \\
\hline $\begin{array}{l}\text { (EIO1EFO2) } \\
\text { Demonstrar interesse ao } \\
\text { ouvir a leitura de poemas } \\
\text { e a apresentação de } \\
\text { músicas. }\end{array}$ & $\begin{array}{l}\text { (EIO2EFO2) } \\
\text { Identificar e criar diferentes } \\
\text { sons e reconhecer rimas e } \\
\text { aliteraçōes em cantigas de } \\
\text { roda e textos poéticos. }\end{array}$ & $\begin{array}{l}\text { (EIO3EFO2) } \\
\text { Inventar brincadeiras } \\
\text { cantadas, poemas e } \\
\text { canções, criando rimas, } \\
\text { aliterações e ritmos. }\end{array}$ \\
\hline $\begin{array}{l}\text { (EIO1EF03) } \\
\text { Demonstrar interesse ao } \\
\text { ouvir histórias lidas ou } \\
\text { contadas, observando } \\
\text { ilustrações e os } \\
\text { movimentos de leitura do } \\
\text { adulto-leitor (modo de } \\
\text { segurar o portador e de } \\
\text { virar as páginas). }\end{array}$ & $\begin{array}{l}\text { (EIO2EFO3) } \\
\text { Demonstrar interesse e } \\
\text { atenção ao ouvir a leitura } \\
\text { de histórias e outros textos, } \\
\text { diferenciando escrita de } \\
\text { ilustraçōes, e acompanhando, } \\
\text { com orientação do adulto- } \\
\text {-leitor, a direção da leitura (de } \\
\text { cima para baixo, da esquerda } \\
\text { para a direita). }\end{array}$ & $\begin{array}{l}\text { (EIO3EFO3) } \\
\text { Escolher e folhear livros, } \\
\text { procurando orientar-se } \\
\text { por temas e ilustrações e } \\
\text { tentando identificar palavras } \\
\text { conhecidas. }\end{array}$ \\
\hline $\begin{array}{l}\text { (EIO1EF04) } \\
\text { Reconhecer elementos das } \\
\text { ilustraçōes de histórias, } \\
\text { apontando-os, a pedido } \\
\text { do adulto-leitor. }\end{array}$ & $\begin{array}{l}\text { (EIO2EFO4) } \\
\text { Formular e responder } \\
\text { perguntas sobre fatos da } \\
\text { história narrada, identificando } \\
\text { cenários, personagens e } \\
\text { principais acontecimentos. }\end{array}$ & $\begin{array}{l}\text { (EIO3EFO4) } \\
\text { Recontar histórias ouvidas } \\
\text { e planejar coletivamente } \\
\text { roteiros de videos e de } \\
\text { encenaçōes, definindo os } \\
\text { contextos, os personagens, } \\
\text { a estrutura da história. }\end{array}$ \\
\hline $\begin{array}{l}\text { (EIO1EFO5) } \\
\text { Imitar as variaçōes de } \\
\text { entonação e gestos } \\
\text { realizados pelos adultos, } \\
\text { ao ler histórias e ao cantar. }\end{array}$ & $\begin{array}{l}\text { (EIO2EFO5) } \\
\text { Relatar experiências e fatos } \\
\text { acontecidos, histórias ouvidas, } \\
\text { filmes ou peças teatrais } \\
\text { assistidos etc. }\end{array}$ & $\begin{array}{l}\text { (EIO3EF05) } \\
\text { Recontar histórias ouvidas } \\
\text { para produção de reconto } \\
\text { escrito, tendo o professor } \\
\text { como escriba. }\end{array}$ \\
\hline
\end{tabular}

Figura 1: Objetivos de aprendizagem e desenvolvimento -

Fonte: http://basenacionalcomum.mec.gov.br/images/BNCC EI EF_110518_versaofinal_site.pdf 


\section{CAMPO DE EXPERIÊNCIAS "ESCUTA, FALA, PENSAMENTO E IMAGINAÇÃO” (Continuação)}

\begin{tabular}{|c|c|c|}
\hline $\begin{array}{l}\text { Bebês (zero a } 1 \text { ano e } \\
6 \text { meses) }\end{array}$ & $\begin{array}{l}\text { Crianças bem pequenas ( } 1 \text { ano } \\
\text { e } 7 \text { meses a } 3 \text { anos e } 11 \text { meses) }\end{array}$ & $\begin{array}{l}\text { Crianças pequenas ( } 4 \text { anos a } \\
5 \text { anos e } 11 \text { meses) }\end{array}$ \\
\hline $\begin{array}{l}\text { (EIO1EF06) } \\
\text { Comunicar-se com } \\
\text { outras pessoas usando } \\
\text { movimentos, gestos, } \\
\text { balbucios, fala e outras } \\
\text { formas de expressão. }\end{array}$ & $\begin{array}{l}\text { (EIO2EFO6) } \\
\text { Criar e contar histórias } \\
\text { oralmente, com base em } \\
\text { imagens ou temas sugeridos. }\end{array}$ & $\begin{array}{l}\text { (EI03EF06) } \\
\text { Produzir suas próprias } \\
\text { histórias orais e escritas } \\
\text { (escrita espontânea), em } \\
\text { situações com função social } \\
\text { significativa. }\end{array}$ \\
\hline $\begin{array}{l}\text { (EIO1EF07) } \\
\text { Conhecer e manipular } \\
\text { materiais impressos e } \\
\text { audiovisuais em diferentes } \\
\text { portadores (livro, revista, } \\
\text { gibi, jornal, cartaz, CD, } \\
\text { tablet etc.). }\end{array}$ & $\begin{array}{l}\text { (EIO2EFO7) } \\
\text { Manusear diferentes } \\
\text { portadores textuais, } \\
\text { demonstrando reconhecer } \\
\text { seus usos sociais. }\end{array}$ & $\begin{array}{l}\text { (EIO3EFO7) } \\
\text { Levantar hipóteses sobre } \\
\text { gêneros textuais veiculados } \\
\text { em portadores conhecidos, } \\
\text { recorrendo a estratégias de } \\
\text { observação gráfica e/ou de } \\
\text { leitura. }\end{array}$ \\
\hline $\begin{array}{l}\text { (EIO1EFO8) } \\
\text { Participar de situações } \\
\text { de escuta de textos } \\
\text { em diferentes gêneros } \\
\text { textuais (poemas, } \\
\text { fábulas, contos, receitas, } \\
\text { quadrinhos, anúncios etc.). }\end{array}$ & $\begin{array}{l}\text { (EIO2EFO8) } \\
\text { Manipular textos e participar } \\
\text { de situações de escuta para } \\
\text { ampliar seu contato com } \\
\text { diferentes gêneros textuais } \\
\text { (parlendas, histórias de } \\
\text { aventura, tirinhas, cartazes de } \\
\text { sala, cardápios, notícias etc.). }\end{array}$ & $\begin{array}{l}\text { (EI03EF08) } \\
\text { Selecionar livros e textos } \\
\text { de gêneros conhecidos para } \\
\text { a leitura de um adulto e/ou } \\
\text { para sua própria leitura } \\
\text { (partindo de seu repertório } \\
\text { sobre esses textos, como a } \\
\text { recuperação pela memória, } \\
\text { pela leitura das ilustrações } \\
\text { etc.). }\end{array}$ \\
\hline $\begin{array}{l}\text { (EIO1EFO9) } \\
\text { Conhecer e manipular } \\
\text { diferentes instrumentos e } \\
\text { suportes de escrita. }\end{array}$ & $\begin{array}{l}\text { (EIO2EFO9) } \\
\text { Manusear diferentes } \\
\text { instrumentos e suportes de } \\
\text { escrita para desenhar, traçar } \\
\text { letras e outros sinais gráficos. }\end{array}$ & $\begin{array}{l}\text { (EIO3EFO9) } \\
\text { Levantar hipóteses em } \\
\text { relação à linguagem escrita, } \\
\text { realizando registros de } \\
\text { palavras e textos, por meio } \\
\text { de escrita espontânea. }\end{array}$ \\
\hline
\end{tabular}

Figura 2: Objetivos de aprendizagem e desenvolvimento (continuação) -

Fonte: http://basenacionalcomum.mec.gov.br/images/BNCC_EI_EF_110518_versaofinal_site.pdf

Observa-se que, apesar de o documento apresentar uma concepção de leitura pautada na discussão e no diálogo e reconhecer que o educador tem a oportunidade de refletir e propor práticas diversas, os objetivos de aprendizagem e desenvolvimento (Figuras 1 e 2) dão fundamento a elaboração de uma extensa lista de atividades. Ao prevalecer objetivos didáticos, o texto do documento minimiza a oportunidade de se construir junto às crianças situações que privilegiam a criatividade. Nesse sentido, o documento, ao tratar o currículo de forma operativa, destaca metas a se alcançar ao final da Educação Infantil que podem restringir outras oportunidades, como o trabalho com projetos de trabalho articulados a uma demanda específica de cada grupo de crianças em seu contexto. Sem dúvida alguma, ter metas é algo constitutivo de um documento legislador. No entanto a ênfase parece recair nas regulamentações e nos objetivos a cumprir. 


\section{A BNCC e os documentos precedentes}

No item anterior destacamos orientações no que tange à leitura para a Educação Infantil nas prescrições da BNCC. Neste item iremos confrontar o texto da BNCC com o documento Referencial Curricular Nacional para a Educação Infantil e com as Diretrizes Curriculares Nacionais para a Educação Infantil, procurando analisar até que ponto encontramos continuidades de enfoques e se há rupturas.

O RCNEI publicado em 1998 apresenta em seus três volumes - Introdução, Formação Pessoal e Social e Conhecimento de Mundo - concepções de criança, de ensino e de trabalho pedagógico. O referido material orientou a Educação Infantil por aproximadamente uma década e abordou a leitura dentro do eixo de trabalho: Linguagem Oral e Escrita.

Segundo expresso no texto, esse eixo de trabalho compreende a relação entre a língua escrita e a oralidade, devendo ambas ser abordadas como frutos de práticas correntes, ou seja, práticas que envolvam as situações sociais de usos. Isso pode ser constatado no trecho a seguir: "elas começam a aprender a partir de informações provenientes de diversos tipos de intercâmbios sociais e a partir das próprias ações, por exemplo, quando presenciam diferentes atos de leitura e escrita" (BRASIL, 1988, p. 122). Dito de outro modo, falar, ler e escrever são ações compreendidas dentro de um contexto próprio, assumindo-se a prática social da linguagem. Por essa perspectiva, as palavras enunciadas ou escritas terão sentido em situações significativas, comunicativas e sociais. O Referencial exprime a linguagem em contextos em que a leitura está articulada a alguma demanda significativa, ligada ao seu cotidiano de uso.

O documento Referencial toma como fundamento das práticas de leitura o conceito de letramento para pautar as atividades com a oralidade, com a escrita e com a leitura. $\mathrm{O}$ termo letramento é explicitado da seguinte forma no texto:

Letramento: produto da participação em práticas sociais que usam a escrita como sistema simbólico e tecnologia. São práticas discursivas que precisam da escrita para torná-las significativas. Dessa concepção decorre o entendimento de que, nas sociedades urbanas modernas não existe grau zero de letramento, pois nelas é impossível não participar, de alguma forma, de algumas dessas práticas (BRASIL, 1998, p. 121).

Por sua vez, a BNCC não se refere ao letramento no campo da Educação Infantil, passando a usar essa referência teórica para o segmento do Ensino Fundamental, na disciplina de Língua Portuguesa. As DCNEI também não explicitam o terno letramento em seu texto, ancorando a leitura em experiências que garantam, a interação das crianças com a literatura (BRASIL, 2010). Nesse ponto, especificamente, observamos uma ruptura na concepção do ensino da leitura, pois ambos os documentos - mais recentes que o RCNEI - não se apoiam (de forma explícita) nos estudos do letramento.

Ainda sobre o RCNEI, ao mesmo tempo que apresenta diferenças em relação à BNCC em alguns aspectos, em outros, apresenta semelhanças. Os dois documentos enfocam o trabalho do professor/educador mediador e a escriba da criança para a produção de textos individuais e coletivos. Também, ambos os documentos descartam práticas escolares mecânicas que priorizem apenas a memorização, o treino e habilidades motoras para aprender a língua escrita.

Em 2010, por outro lado, com a publicação das DCNEI a Educação Infantil passa a ser focada de modo menos prescritivo, em que o trabalho pedagógico em creches e pré-escolas recebe maior abertura e autonomia. As DCNEI aproximam-se de estudos e fundamentos da Sociologia da Infância, os quais defendem que as crianças devem ser vistas em sua multiplicidade de forma singular e como produtoras de cultura. Nessa perspectiva, o ensino, o 
conteúdo, o aluno, são nomenclaturas que não caracterizam mais a Educação Infantil, pelo contrário, passam a ser vistas como pertencentes ao quadro de discursos que escolarizam as crianças aos moldes do Ensino Fundamental.

A leitura é destacada no artigo $11^{\circ}$ das DCNEI, em que trata das Práticas Pedagógicas da Educação Infantil. Neste artigo consta que as propostas pedagógicas devem garantir experiências nas mais variadas linguagens e conhecimentos, dentre estes, a língua escrita é enfatizada e os professores precisam garantir que as crianças tenham "experiências de narrativas, de apreciação e interação com a linguagem oral e escrita, e convívio com diferentes suportes e gêneros textuais orais e escritos" (BRASIL, 2010, p. 25).

O texto da BNCC produz, em relação a esse aspecto, uma continuidade ao documento das Diretrizes. A leitura no atual documento, também é destacada em experiências narrativas, enfocando os diferentes gêneros textuais. Ainda, os dois documentos - BNCC e DCNEI - enfatizam a realização de brincadeiras cantadas e de poesias para aproximar as crianças da leitura.

\section{Considerações finais}

Conforme explicitado antes, ao analisar o que se refere à leitura no trabalho pedagógico com crianças pequenas apresentada na Base Nacional Comum Curricular (BNCC) para a Educação Infantil, constatamos algumas continuidades e rupturas entre esse documento e os antigos materiais norteadores do MEC - Referencial Curricular Nacional para a Educação Infantil (RCNEI) e as Diretrizes Curriculares Nacionais para a Educação Infantil (DCNEI).

Ao buscar orientar e regulamentar os conteúdos para a Educação Infantil, os documentos oficiais do MEC, apresentaram ao longo do tempo diferentes concepções acerca da leitura. $\mathrm{O}$ RCNEI no final da década dos anos 1990 aborda a leitura em propostas de atividades permanentes e cotidianas nas salas de crianças pequenas. Apresentou o professor como mediador entre os textos e as crianças e ainda se ancorou teoricamente no conceito de letramento para fundamentar atividades que buscam aproximar a leitura da prática social. Em 2010, as DCNEI apresentaram uma proposta mais aberta e autônoma às unidades escolares, abordando a leitura como uma das diversas maneiras de manifestação cultural e social, e apresentando situações sobre como a leitura e outras linguagens deveriam ser trabalhadas na Educação Infantil. Atualmente, com a BNCC, a leitura integra lugar dentro de um dos campos de experiência descritos no material de orientação e é compreendida no contato e convívio com diferentes textos e em diferentes suportes, sendo também tomada como disparadora de conversas e diálogos.

Portanto, ao observar essas continuidades e algumas mudanças no modo de fundamentar o trabalho com a leitura nos documentos oficiais, o que se se observa é que se expressa no texto uma preocupação maior em estruturar e disciplinar mais o currículo, não se detendo tanto nos fundamentos da leitura como prática social de uso da língua.

\section{Referências}

BICALHO, Delaine Cafiero. CEALE - Centro de alfabetização, leitura e escrita da UFMG. [2015?]. Disponível em: http://ceale.fae.ufmg.br/app/webroot/glossarioceale/verbetes/leitura. Acesso em: 05 de março de 2020.

BRASIL. Base Nacional Comum Curricular. 2017. Disponível em: http://portal.mec.gov.br/index.php?option=com_docman\&view=download\&alias=79601ane o-texto-bncc-reexportado-pdf-2\&category_slug=dezembro-2017-pdf\&Itemid=30192. Acesso em: 03 de março de 2020. 
BRASIL. Diretrizes Curriculares Nacionais para a Educação Infantil. Brasília, DF, 2010. Disponível em: https://ndi.ufsc.br/files/2012/02/Diretrizes-Curriculares-para-a-E-I.pdf. Acesso em: 03 de março de 2020.

BRASIL. Referencial curricular nacional para a Educação Infantil. Volume: Introdução. Ministério da Educação e do Desporto, Secretaria de Educação Fundamental. Brasília: MEC/SEF, 1998.

BRASIL. Referencial curricular nacional para a Educação Infantil. Volume: Conhecimento de mundo. Ministério da Educação e do Desporto, Secretaria de Educação Fundamental. Brasília: MEC/SEF, 1998.

BRASIL. Lei de Diretrizes e Bases da Educação Nacional. Lei número 9394, 20 de dezembro de 1996. Disponível em: http://www.planalto.gov.br/ccivil_03/leis/19394.htm. Acesso em: 05 de março de 2020.

BRASIL. Constituição da República Federativa do Brasil. Brasília, DF: Senado Federal. 1988. Disponível em: http://www.planalto.gov.br/ccivil_03/constituicao/constituicao.htm. Acesso em: 03 de março de 2020.

FOUCAULT, M. Microfísica do Poder. Tradução: Roberto Machado. Rio de Janeiro: Graal, 1988.

FREIRE, P. Pedagogia da Autonomia: saberes necessários à prática educativa. São Paulo: Paz e Terra, 1996 (Coleção Leitura).

FREIRE, Paulo. A importância do ato de ler: em três artigos que se completam. São Paulo: Autores Associados: Cortez, 1989.

GINZBURG, Carlo. Sinais: raízes de um paradigma indiciário. In: GINZBURG, Carlo. Mitos, emblemas, sinais: morfologia e história. Companhia das Letras, 1989.

GODOY, Arilda Schmidt. Pesquisa Qualitativa Tipos Fundamentais. Revista de Administração de Empresas São Paulo, v. 35, n. 3, p. 20-29, maio/jun. 1995. Disponível em: http://www.scielo.br/pdf/rae/v35n3/a04v35n3.pdf. Acesso em: 06 de março de2020.

SILVA, Ezequiel Theodoro da. Unidades de leitura - Trilogia pedagógica. Campinas, SP: Autores Associados, 2003.

\section{Sobre as autoras}

Mellina Silva é mestranda pela Universidade Estadual de Campinas, na Faculdade de Educação, no Grupo de Pesquisa Alfabetização, Leitura e Escrita/Trabalho Docente na Formação Inicial (ALLE/AULA). É professora da Educação Infantil no Centro de Convivência Infantil (CECI) da UNICAMP. Foi professora da educação básica no município de Hortolândia de 2005 a 2014. Tem experiência nas áreas de alfabetização e letramento.

E-mail: mellina@unicamp.br. 
Ana Lúcia Guedes-Pinto possui graduação em Pedagogia pela UNICAMP (1990), Mestrado em Educação pela FE/UNICAMP (1994), Doutorado em Linguística Aplicada pelo IEL/UNICAMP (2000) e Livre Docência na área de Teoria Pedagógica pela FE/UNICAMP (2011). Atualmente é Professora Titular do Departamento de Ensino e Práticas Culturais, da Faculdade de Educação da Unicamp. É líder do grupo de pesquisa Letramento do Professor (IEL-UNICAMP) e vice-líder do grupo ALLE/AULA (FE/UNICAMP).

E-mail: alguedes@mpc.com.br. 